\title{
Natural Nanominerals Show Enzyme-Like Activities
}

\author{
Feng Feng $\mathbb{D}^{1}{ }^{1}$ Peixia Wang, ${ }^{2,3,4}$ Yihe Zhang $\mathbb{D},{ }^{1}$ Qi An, ${ }^{1}$ Yue Lin, ${ }^{5}$ Wangshu Tong, \\ Paul K. Chu $\mathbb{D},{ }^{6,7}$ and Minmin Liang $\mathbb{D}^{4}$
}

${ }^{1}$ Beijing Key Laboratory of Materials Utilization of Nonmetallic Minerals and Solid Wastes, National Circular Economy Engineering Laboratory, National Laboratory of Mineral Materials, School of Materials Science and Technology, China University of Geosciences, Beijing 100083, China

${ }^{2}$ Institute of Molecular Medicine, Peking University, Beijing 100871, China

${ }^{3}$ Peking-Tsinghua Center for Life Sciences, Peking University, Beijing 100871, China

${ }^{4}$ Experimental Center of Advanced Materials School of Materials Science and Engineering, School of Materials Science and Engineering, Beijing Institute of Technology, Beijing 100081, China

${ }^{5}$ College of Information and Electrical Engineering, China Agriculture University, Beijing 100083, China

${ }^{6}$ Department of Physics, City University of Hong Kong, Tat Chee Avenue, Kowloon, Hong Kong 999077, China

${ }^{7}$ Department of Materials Science and Engineering, City University of Hong Kong, Tat Chee Avenue, Kowloon, Hong Kong 999077, China

Correspondence should be addressed to Yihe Zhang; zyh@cugb.edu.cn and Minmin Liang; mmliang@bit.edu.cn

Received 30 May 2020; Revised 17 March 2021; Accepted 27 May 2021; Published 8 July 2021

Academic Editor: Filippo Giubileo

Copyright (C) 2021 Feng Feng et al. This is an open access article distributed under the Creative Commons Attribution License, which permits unrestricted use, distribution, and reproduction in any medium, provided the original work is properly cited.

\begin{abstract}
Natural nanominerals (NNMs) are progressively deposited during earth's formation. They have shown a broad range of applications from industrial catalysis, environmental treatment, and earth science to pharmaceutics due to their unique nanostructures and characteristics. Here, we first report that NNMs have intrinsic enzyme-like properties and show good biocompatibility. First, we characterized the morphology and structure of the six most representative NNMs including sepiolite, attapulgite, halloysite, montmorillonite, kaolinite, and diatomite by SEM, TEM, and XRD. Then, we quantitatively tested their peroxidase- (POD-), catalase- (CAT-), oxidase- (OXD-), and superoxide dismutase- (SOD-) like activities. The results indicate that different kinds of NNMs show varying degrees of POD-like, CAT-like, and SOD-like activities and minor OXD-like activity. Finally, we tested their cytotoxicity and found that the selected representative NNMs have no or less influence on cell viability, showing high biosafety. At present, NNMs have been widely used, mostly focusing on the physical and chemical properties, such as luminescence and conductivity. Our work promotes the understanding of NNMs, providing a new direction for the better application of NNMs.
\end{abstract}

\section{Introduction}

Natural enzymes are biocatalysts that facilitate a majority of biological reactions that occur in living systems [1]. Natural enzymes exhibit the advantages of high catalytic efficiency and specificity; thus, they have shown a broad range of applications in biology and medicine. However, natural enzymes are expensive, have ease of denaturation, and are laborious to prepare, which greatly limit their practical applications $[2,3]$. In order to solve these problems, many efforts have been made, including genetic or chemical modification $[4,5]$ and development of artificial enzymes $[6,7]$.

Artificial enzymes are compounds synthesized by mimicking the structure and function of natural enzymes. They are prepared to overcome the drawbacks of a natural enzyme and thus have the advantages of high stability, low cost, longterm storage, etc. Nanozymes are nanomaterials with the intrinsic enzyme-like properties $[8,9]$. As a new type of promising artificial enzyme, nanozymes have gained a lot of applications from in vitro detection to in vivo monitoring $[10-12]$ and therapy owing [13-17] to their obvious 
advantages over natural enzymes and conventional artificial enzymes, such as low cost, high production, and tunable catalytic activities. Until now, more than 500 nanomaterials with different composites and structure have been reported to have enzyme-like activities. The activities mainly focus on oxidoreductases, hydrolases, lyases, and so on. Among them, POD, OXD, CAT, and SOD are the most typical and widely used in artificial nanozymes.

With the development of nanobiology and nanotechnology, the application of nanomaterials has extended from in vitro detection and analysis to in vivo disease diagnosis and treatment. The biological effects of nanomaterials are currently the biggest challenge for further clinical transformation. Materials with good enzyme-like activities and biocompatibility are of great significance for biomedicine. In recent years, NNMs show great potential in biomedicine.

NNMs are made by nature through biogeochemical processes. They are multicomposed of oxygen, silicon, aluminum, iron, calcium, etc., which are the most abundant and nontoxic elements in the crust of earth. They present chemical, physical, and electrical properties that change as a function of the size and shape of the material $[18,19]$. NNMs have the characteristics of nanosize, large specific surface area, high surface energy, good biocompatibility, multiple surface-active sites, large quantity, low cost, etc., and they also have three unique nanosize effects, namely, surface, small size, and macroscopic quantum tunneling effects [20-23]. Based on these, NNMs have been broadly applied in biomedicine development; for instance, attapulgite has been widely used in tissue engineering and osteoblast differentiation [24, 25]; sepiolite has been widely used as a graft material and a bioelectrocatalyst [26]; montmorillonite has been used as a protective agent for intestinal mucosa due to its strong surface adsorption ability [27]; and diatomite has been used as drug delivery system and contrast medium $[28,29]$. Currently, the application of NNMs mainly focuses on their nanostructure and electrochemical properties. As to details, the surface of attapulgite is permanently negatively charged, which is conducive to the formation of cation exchange capacity to combine molecules with positive points on the surface. Wang et al. developed a new type of nonenzyme glucose electrogenerated chemiluminescence (ECL) sensor with good repeatability, wide linear range, high sensitivity, and good stability based on the integration of attapulgite and semiconductor titanium dioxide [30]. Based on good packaging and slow-release characteristics of halloysite, Zhang et al. prepared a novel halloysite-based hydrogel with a "turn-on" fluorescence character upon $\mathrm{H}_{2} \mathrm{O}_{2}$ and used it to construct a $\mathrm{H}_{2} \mathrm{O}_{2}$-responsive drug delivery system in which a coprecipitation method was proposed to afford the drugloaded halloysite nanotubes [31]. Bacterial cellulose is a promising biopolymer with wound healing and tissue regeneration properties, but its lack of antibacterial property limits its biomedical applications. Research by Sajjad et al. suggested that the wound healing properties of bacterial cellulose should be combined with the antibacterial activity of modified montmorillonite to design new artificial burn substitutes [32].

With the rising of enzymology, NNMs also have corresponding reports on artificial enzymes or composites about enzymes. Zhang et al. synthesized chitosan-halloysite hybrid nanotubes through the assembly of chitosan onto halloysite, and the composite showed excellent capacity for immobilization of horseradish peroxidase (HRP) through cross-linking by glutaraldehyde, exhibiting overall high removal efficiency for phenol from wastewater [33]. Liang et al. verified that attapulgite enhances the production of methane from anaerobic digestion of pig slurry by changing enzyme activities and microbial community [34]. Sun et al. researched on assessment of natural sepiolite on cadmium stabilization, microbial communities, and enzyme activities in acidic soil [35]. However, most of them regard NNMs as immobilization car of enzyme and focus on the influence of NNMs on proteinbased enzyme, and enzyme-like activity of NNMs themselves needs to be researched.

Here, we discover for the first time that NNMs have the intrinsic enzyme-like activities and can be used as an ideal alternative to protein-based enzymes. Since the proteinbased enzymes or artificial enzymes are greatly demanded in disease diagnosis [36] and treatment [37, 38], NNMs, as a new kind of natural biomaterials, would have potential applications in biomedicine development by combining their intrinsic enzyme-like activities and unique electrochemical characteristics.

In this study, based on NNMs themselves, six typical NNMs were selected to be tested. In addition to basic characterization including TEM, SEM, and XRD, the four types of enzyme-like activities were studied. In order to make the application of NNMs in the field of biomedicine more valuable, we have also studied their biocompatibility. This work provides a certain reference for the following research on the application of NNMs in nanozyme.

\section{Materials and Methods}

2.1. Materials. The NNMs were obtained from different places: attapulgite was purchased from Yuanheng Water Purification Materials Company, Gongyi City, Henan Province, China; halloysite was obtained from Runwo Material Technology Co., Ltd., Guangdong Province, China; sepiolite was obtained from Spain; montmorillonite was obtained from Xinyu Bentonite Company, Kazuo City, Liaoning Province, China; kaolinite was bought from Xuyi City, Jiangsu Province, China; and diatomite was obtained from Haiyang Powder Technology Co., Ltd., Shenzhen City, Guangdong Province, China. All of NNMs were screened, with good purity and quality, through the companies from which they originate, and were UV sterilized for 1 hour before use.

$\mathrm{H}_{2} \mathrm{O}_{2}, 3,3^{\prime}, 5,5^{\prime}$-tetramethylbenzidine (TMB), 3,3' -diaminobenzidine tetrahydrochloride (DAB), and $\mathrm{O}$-phenylenediamine (OPD) were purchased from Sigma-Aldrich; the SOD assay kit and the CCK-8 cell viability kit were purchased from Dojindo Molecular Technologies.

\subsection{Methods}

2.2.1. Characterization of NNMs. The structure and morphology of the NNMs were characterized by transmission 

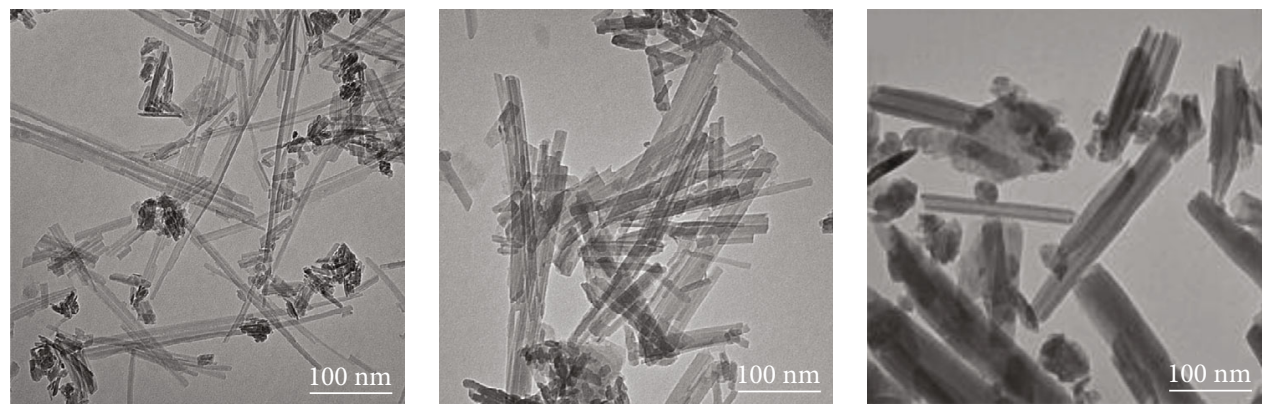

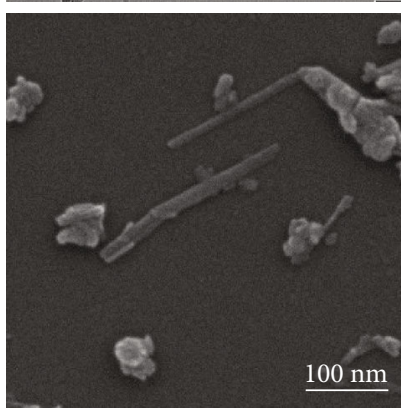

(a)
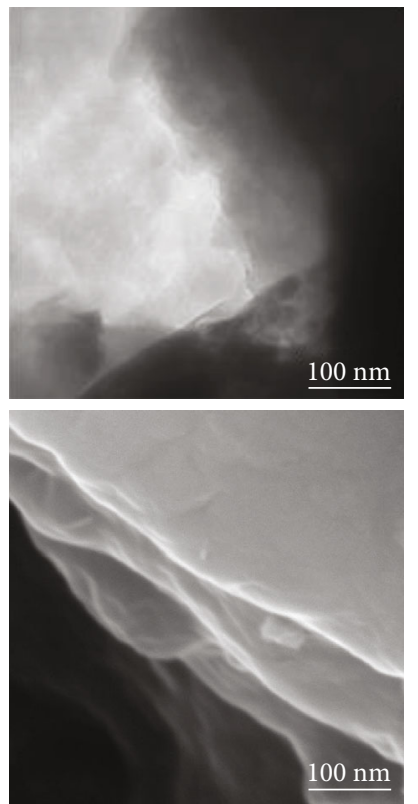

(d)

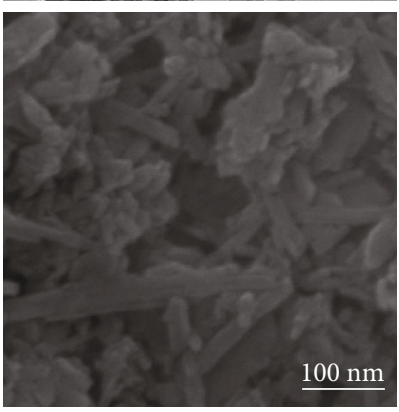

(b)
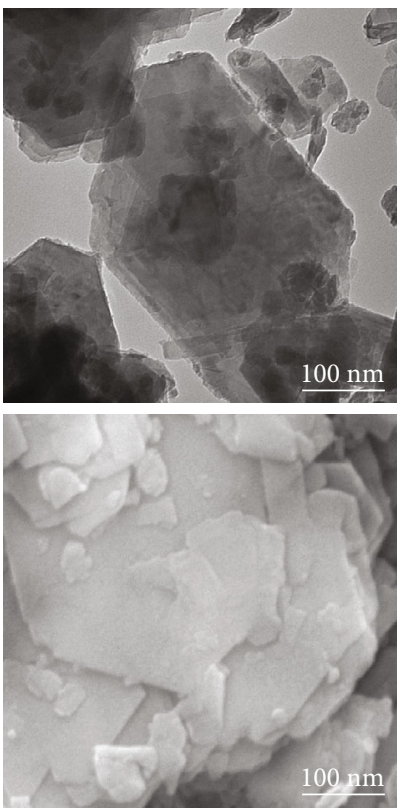

(e)

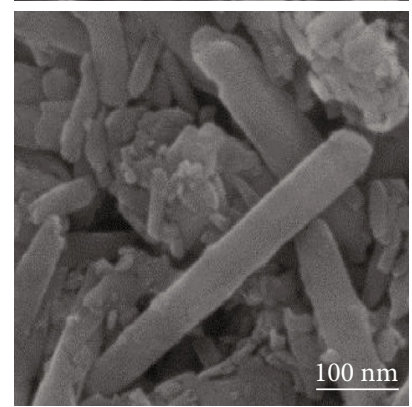

(c)
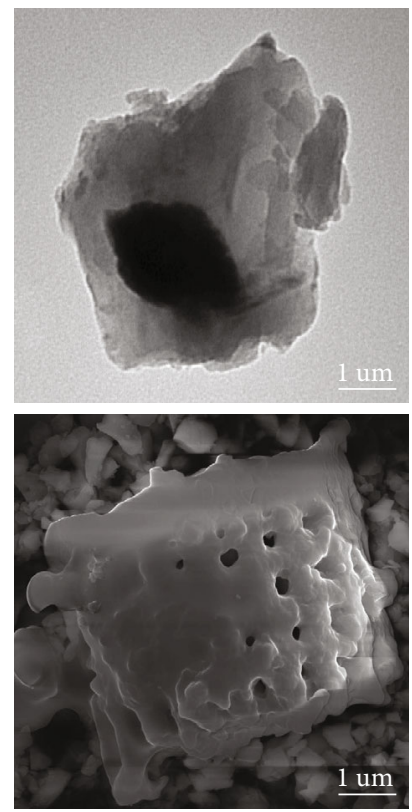

(f)

Figure 1: The morphology of the representative NNMs: (a) Sepiolite; (b) attapulgite; (c) halloysite; (d) montmorillonite; (e) kaolinite; (f) diatomite. The top line is the TEM results, and the bottom line is the corresponding SEM images.

electron microscopy (TEM) and scanning electron microscope (SEM). For TEM, the diluted NNMs were applied to a holey grid and dried at room temperature. The dried samples were imaged with a FEI Tecnai Spirit operated at $120 \mathrm{kV}$. For SEM, the diluted NNMs were applied to conductive adhesive and dried at room temperature. The dried samples were observed with a Hitachi JSM-7001F SEM at a voltage of $15 \mathrm{kV}$. The crystal structure of NNMs was characterized by a D8 Advance X-ray Diffractometer (XRD), with an angular scanning from $5^{\circ}$ to $80^{\circ}$. The
Brunauer-Emmett-Teller (BET) specific surface area was performed on a Quantachrome Autosorb-iQ instrument ( $\mathrm{N}_{2}$ adsorption).

2.2.2. POD-Like Activity of NNMs. The POD-like activity of the NNMs was characterized using a colorimetric assay. Briefly, $50 \mu \mathrm{g} / \mathrm{mL}$ of NNMs was mixed with $1 \mathrm{M} \mathrm{H}_{2} \mathrm{O}_{2}$ in $0.2 \mathrm{M}$ sodium acetate buffer ( $\mathrm{pH} 3.6$ ) using $0.5 \mathrm{mg} / \mathrm{mL}$ of $\mathrm{TMB}$ as the colorimetric substrate. Color reaction was recorded every $10 \mathrm{~s}$ for up to $600 \mathrm{~s}$. 

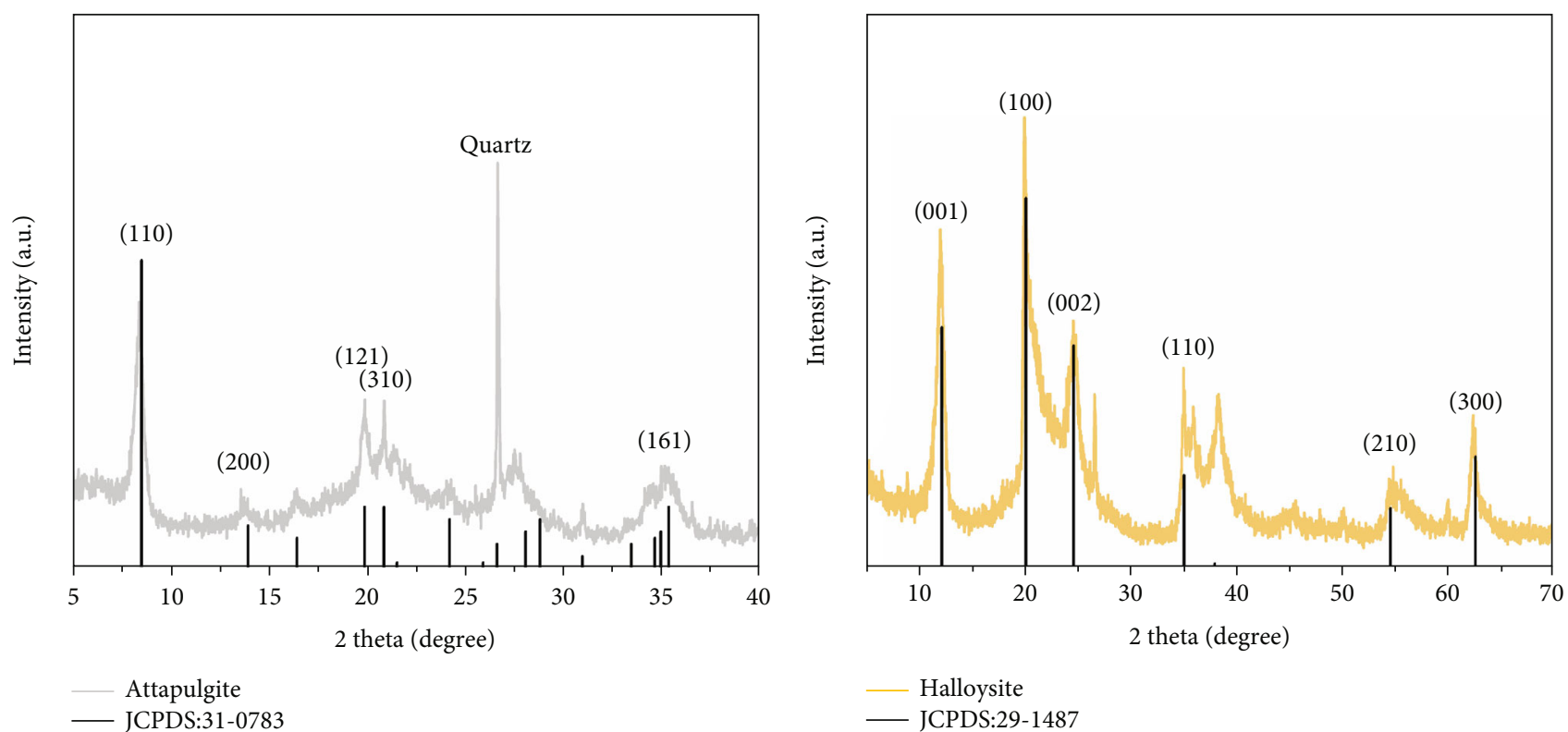

(a)

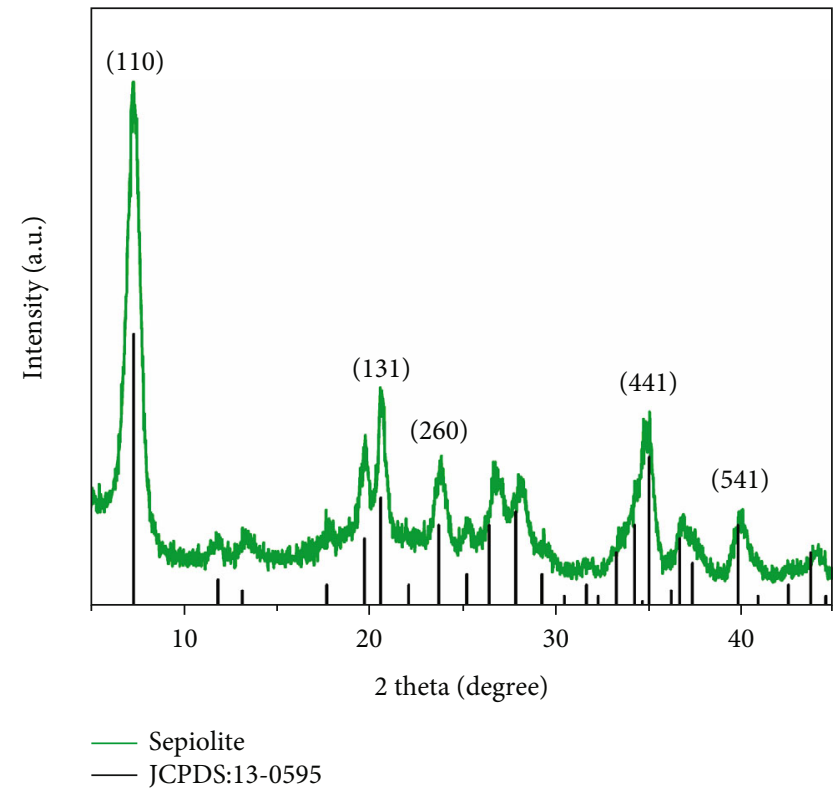

(c)

(d)

Figure 2: Continued. 


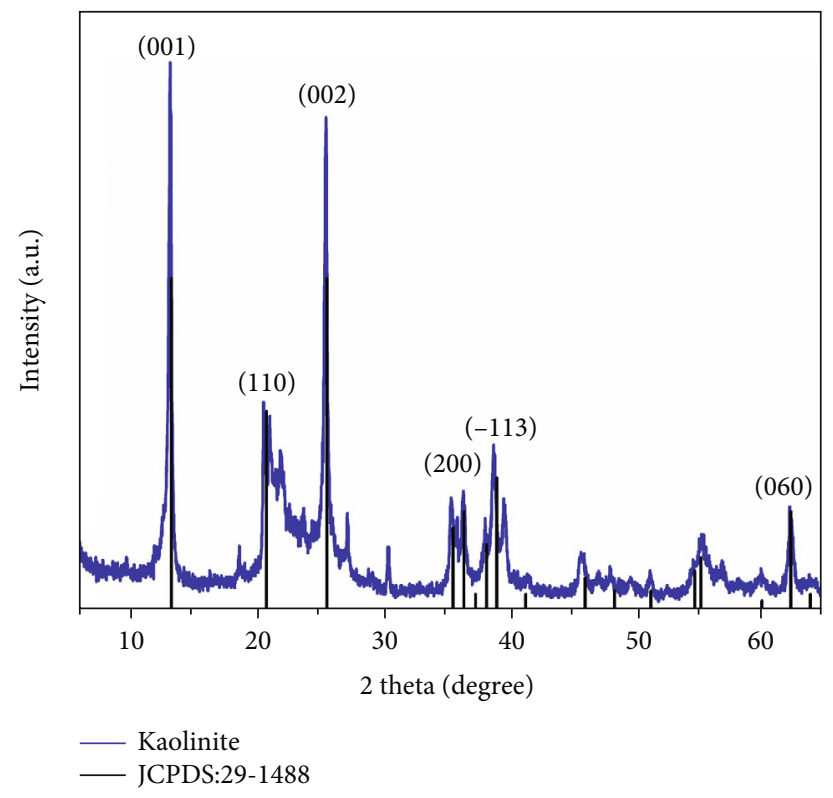

(e)

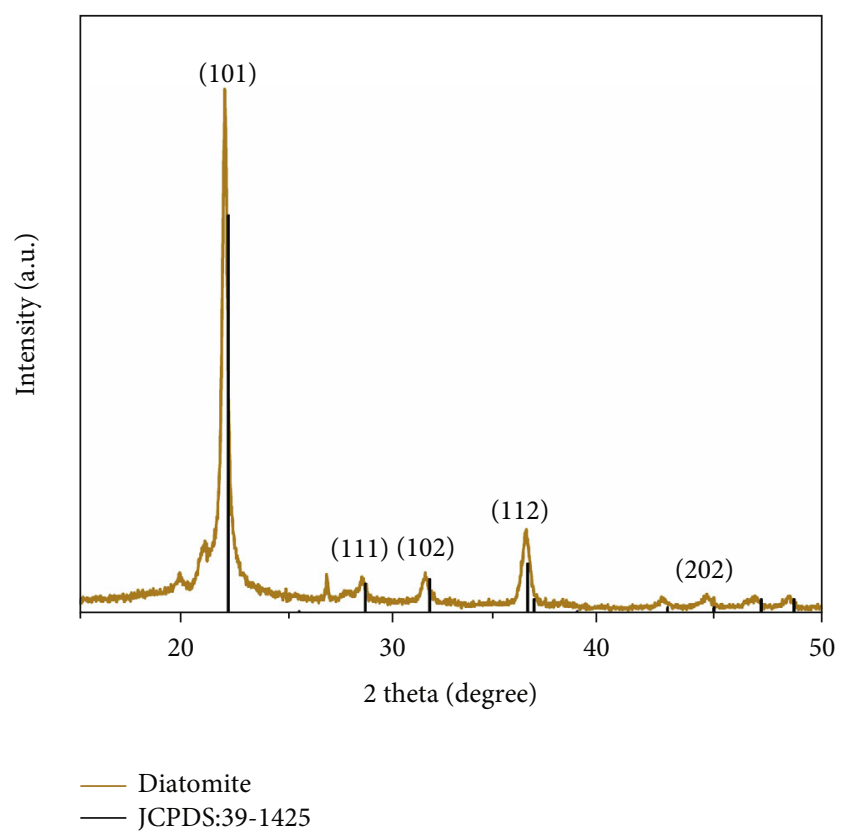

(f)

FIGURE 2: The XRD spectrum and corresponding standard cards of the representative NNMs: (a) attapulgite; (b) halloysite; (c) sepiolite; (d) montmorillonite; (e) kaolinite; (f) diatomite.

2.2.3. CAT-Like Activity of NNMs. CAT-like activity of NNMs was carried out at room temperature by measuring the generated $\mathrm{O}_{2} .100 \mu \mathrm{g}$ NNMs was dispersed into $5.0 \mathrm{~mL}$ PBS (pH 7.0), and then, $250 \mu \mathrm{L} 30 \% \mathrm{H}_{2} \mathrm{O}_{2}$ solution was added to the mixture. The solubility of generated $\mathrm{O}_{2}$ (unit: $\mathrm{mg} / \mathrm{L}$ ) was measured at different reaction times.

2.2.4. OXD-Like Activity of NNMs. The assay of the OXD-like activity of NNMs was similar to the POD-like activity. The NNMs were dispersed in HAc-NaAc buffer ( $\mathrm{pH} 4.5$ ). Then, $100 \mu \mathrm{L}$ and $10 \mathrm{mg} / \mathrm{mL}$ of TMB were added to the quartz cuvette, and the absorbance at $652 \mathrm{~nm}$ was recorded every $10 \mathrm{~s}$ for up to $600 \mathrm{~s}$.

2.2.5. SOD-Like Activity of NNMs. The SOD-like activity of NNMs was measured under the manufacturer's instructions of a commercial SOD assay kit. The SOD-like activity of NNMs was expressed as the inhibition rate of the NNMs on WST reaction.

2.2.6. Cell Culture and Biosafety Assay. The human hepatocellular carcinoma cell line (HepG2) was purchased from American Type Culture Collection (ATCC) and cultured in RPMI 1640 medium supplemented with 10\% fetal bovine serum and $1 \%$ penicillin-streptomycin. Cell cytotoxic analysis was evaluated by a CCK-8 cell viability kit. Briefly, 4000 HepG2 cells were placed to a 96-well plate and cultured in an incubator for 24 hours. The NNMs treated by ultrasound were diluted in the medium and then added into the cells. After 24 hours of incubation, the NNMs were removed and $100 \mu \mathrm{L}$ of CCK-8 solution was added into each well. After incubating for an additional 3 hours, the absorbance at $450 \mathrm{~nm}$ was detected by a microplate reader.
2.2.7. Statistical Analysis. All the results were expressed as means \pm SE from three parallel repeats. All the raw data was processed through the GraphPad Prism 7.0 software and Origin 2018.

\section{Results and Discussion}

3.1. The Structure and Morphology of NNMs. We first characterize the structure and morphology of the selected six NNMs by SEM and TEM (Figure 1). Sepiolite is a kind of hydrous magnesium silicate with the theoretical formula of $\mathrm{Si}_{12} \mathrm{Mg}_{8} \mathrm{O}_{30}(\mathrm{OH})_{4}\left(\mathrm{H}_{2} \mathrm{O}\right)_{4} \cdot 8 \mathrm{H}_{2} \mathrm{O}$ [39] (Figure 1(a)). It has a well-dispersed acicular structure. The diameter of sepiolite is about $10-30 \mathrm{~nm}$, and the length is several hundred nanometers, which give it a huge surface area to load a drug or a catalyst [40]. Attapulgite, with the theoretical chemical formula of $\mathrm{Mg}_{5} \mathrm{Si}_{8} \mathrm{O}_{20}(\mathrm{OH})_{2}\left(\mathrm{OH}_{2}\right)_{4} \cdot 4 \mathrm{H}_{2} \mathrm{O}$ [41-43], has a nanorod structure that is $10-50 \mathrm{~nm}$ in diameter, and some can aggregate to be fibrous bunches, indicating the strong adsorption in the surface (Figure 1(b)). The halloysite nanotube belongs to aluminosilicate with the general chemical formula of $\mathrm{Al}_{2} \mathrm{Si}_{2} \mathrm{O}_{5}(\mathrm{OH})_{4} \cdot \mathrm{nH}_{2} \mathrm{O}$. And it has a hollow tubular structure with an inner diameter of $20-40 \mathrm{~nm}$ and lengths ranging from 200 to $1000 \mathrm{~nm}$ (Figure 1(c)). There are two forms existing in halloysite, namely, an anhydrous form with a layer spacing of $\sim 7 \AA$ [44-46] and a hydrated form with a layer spacing of $\sim 10 \AA$, which give it potential for designing with medicines for different needs. Montmorillonite is a typical layered mineral structure formed by single layer of tens to hundreds of nanometers, with a chemical formula of $(\mathrm{Na}, \mathrm{Ca})_{0.33}(\mathrm{Al}, \mathrm{Mg})_{2}\left[\mathrm{Si}_{4} \mathrm{O}_{10}\right](\mathrm{OH})_{2} \cdot \mathrm{nH}_{2} \mathrm{O}[47,48]$, which has a high water swell ability due to water and some exchange cations in crystal structure layers. In Figure 1(d), we can 


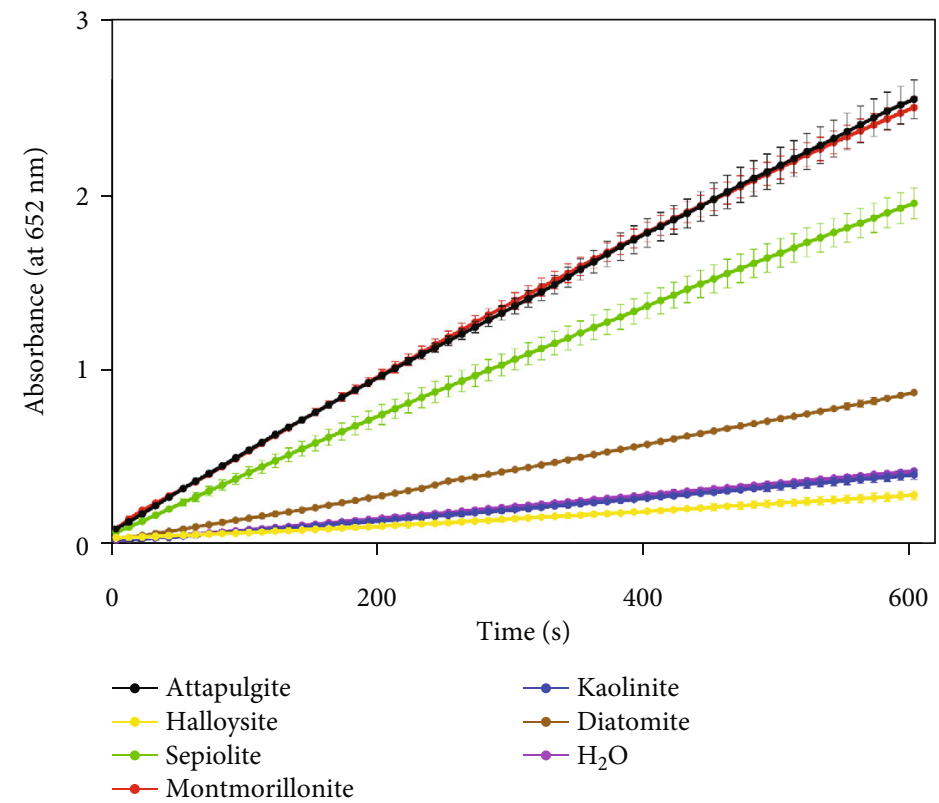

(a)

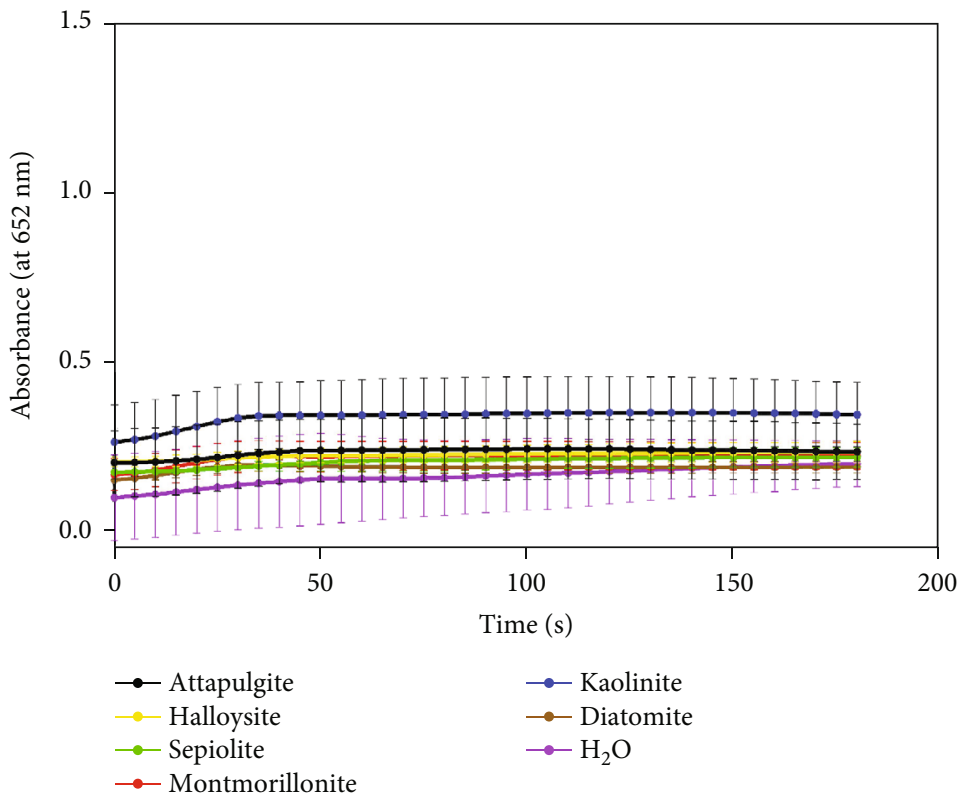

(b)

Figure 3: Continued. 


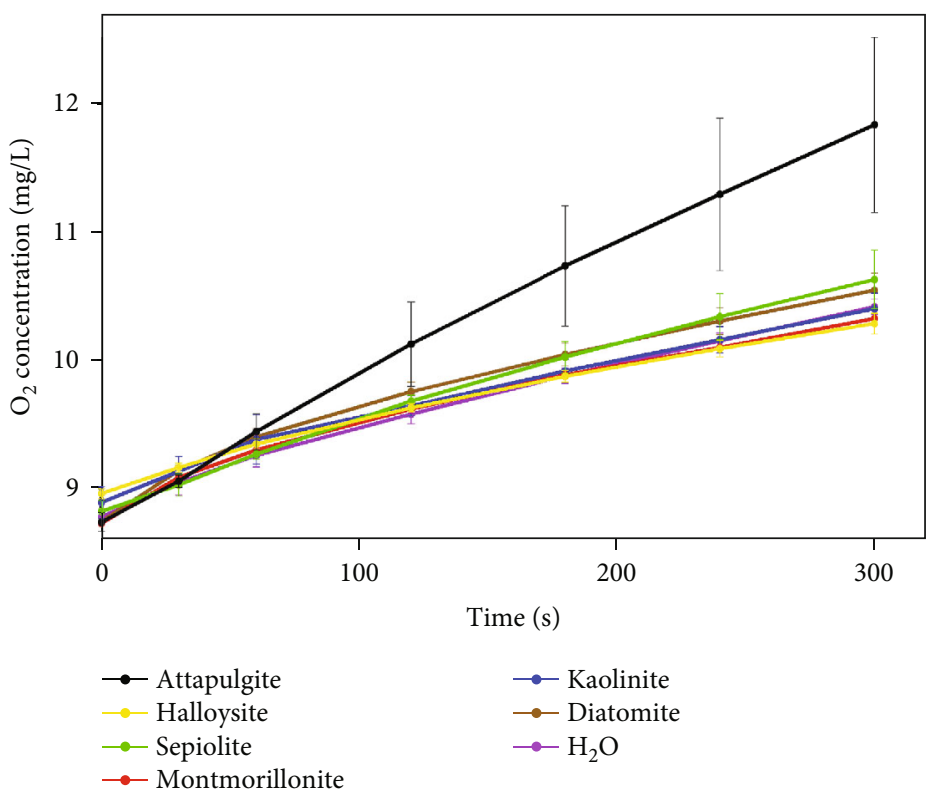

(c)

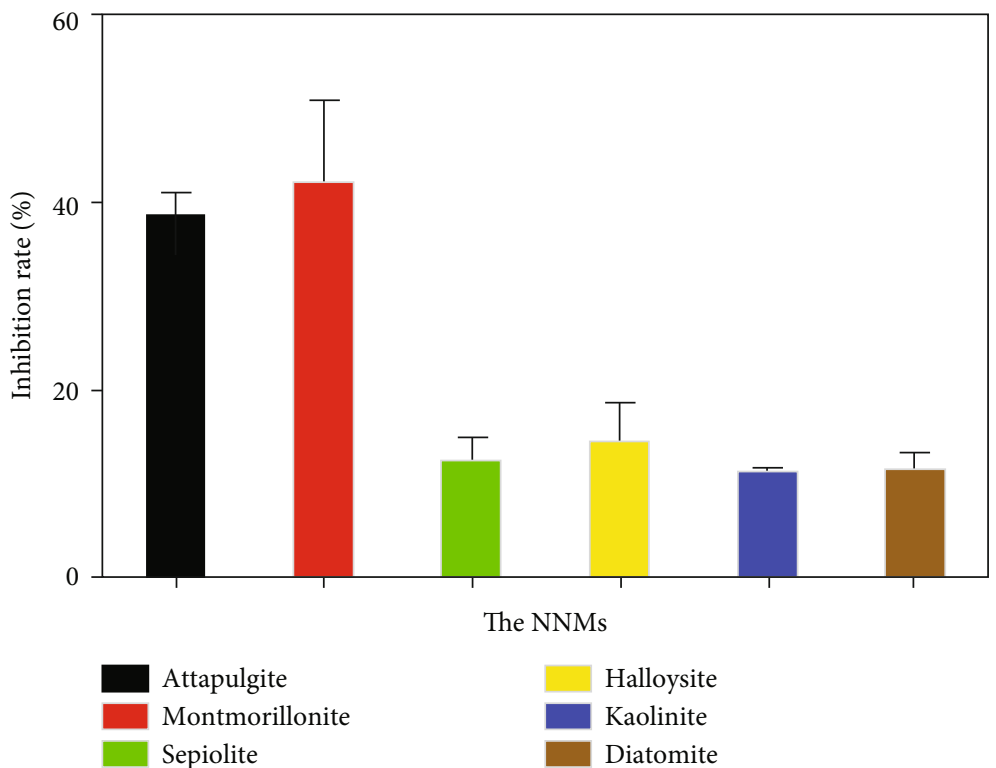

(d)

FIGURE 3: The enzyme-like activities of the representative NNMs: (a) POD-like; (b) OXD-like; (c) CAT-like; (d) SOD-like.

clearly see the layered structure of montmorillonite, which can be used to load molecules. Kaolinite has stacked layers with the general molecular formula of $\mathrm{Al}_{2} \mathrm{O}_{3} \cdot 2 \mathrm{SiO}_{2} \cdot 2 \mathrm{H}_{2} \mathrm{O}$ [49], and it is usually a self-shaped hexagonal plate, semiself-shaped, or shape-like crystal with a spacing of several tens of nanometers (Figure 1(e)). Diatomite is a hydrous form of silica or opal composed of a siliceous skeleton, and it shows a beautiful tubular structure with uniform holes in the surface, which gives it a strong adsorption capacity and possibility of surface modification (Figure 1(f)).

Verifying the types of NNMs accurately is important for subsequent work. The phase of these samples is characterized by XRD. As shown in Figures 2(a)-2(f), by comparing the diffraction peaks with the standard cards, it is confirmed that the materials are correspondingly attapulgite, halloysite, sepiolite, montmorillonite, kaolinite, and diatomite, respectively [50-55].

3.2. The Enzyme-Like Activities of the NNMs. For POD, we use TMB as the catalytic substrate and record the absorbance at $652 \mathrm{~nm}$ every $10 \mathrm{~s}$. The result shows that NNMs can catalyze the oxidation of TMB (peroxidase substrate) in the presence of $\mathrm{H}_{2} \mathrm{O}_{2}$ to produce colorimetric reactions (Figure 3(a)), showing the POD-like activity of NNMs toward typical peroxidase substrate. The selected attapulgite, montmorillonite, and sepiolite present a strong POD-like activity. We next characterize if the NNMs can directly oxidize the TMB without adding $\mathrm{H}_{2} \mathrm{O}_{2}$. We found that all the tested NNMs show 
TABLE 1: The surface area of six kinds of NNMs.

\begin{tabular}{lcccccc}
\hline NNMs & Attapulgite & Halloysite & Sepiolite & Montmorillonite & Kaolinite & Diatomite \\
\hline Surface area $\left(\mathrm{m}^{2} / \mathrm{g}\right)$ & 129.415 & $50[58]$ & 248.342 & 42.638 & 21.709 & $76.9[59]$ \\
\hline
\end{tabular}

little OXD-like activity for TMB (Figure 3(b)), confirming the POD-like activity of NNMs.

We then characterize the CAT- and SOD-like activities of the selected NNMs. As shown in Figures 3(c) and 3(d), all the NNMs show the ability to relieve oxidative stress. Attapulgite shows both high catalytic abilities of decomposing $\mathrm{H}_{2} \mathrm{O}_{2}$ and removing ${ }^{\circ} \mathrm{O}_{2}^{-}$, and montmorillonite shows the highest SODlike activity among the tested NNMs.

As for the difference of enzyme-like activity of NNMs, the compound and surface area may be the possible keys. From our results, attapulgite and montmorillonite show high POD-like activities. We guess it is because they contain iron $[56,57]$, which is also contained in HRP. In addition, the surface area may also be the key point for activities. Our result shows that the POD-like activity of sepiolite is higher than that of diatomite, which is consistent with their surface area (sepiolite is $248.342 \mathrm{~m}^{2} / \mathrm{g}$; diatomite is $76.9 \mathrm{~m} / \mathrm{g}$; details are shown in Table 1). While when the surface area is below $50 \mathrm{~m}^{2} / \mathrm{g}$, there is no obvious difference for activities.

3.3. Color Reaction Catalyzed by the NNMs. Peroxidase can catalyze the oxidation of colorimetric substrates, such as $\mathrm{TMB}, \mathrm{DAB}$, and $\mathrm{OPD}$, to give a color reaction. Thus, the POD-like activity of artificial enzymes has been widely used for sensing, immunoassay, and imaging. The NNMs also show the high POD-like activity by catalyzing the oxidation of $\mathrm{TMB}, \mathrm{DAB}$, and $\mathrm{OPD}$ to produce a strong color reaction (Figure 4).

3.4. Biosafety Assay. Importantly, we test the bioeffects of NNMs on cell viability (Figure 5). The results show that attapulgite, halloysite, kaolinite, and diatomite are nontoxic to HepG2 cells even at a high concentration of $250 \mu \mathrm{g} / \mathrm{mL}$. Montmorillonite is relatively safe at the concentration below $125 \mu \mathrm{g} / \mathrm{mL}$, while the cell activity can be inhibited above $125 \mu \mathrm{g} / \mathrm{mL}$. Sepiolite shows strong cytotoxicity at the tested concentration, suggesting that we should pay attention to its biotoxicity when used in vivo.

\section{Discussion}

In this work, we mainly elaborate the intrinsic biological properties (i.e., enzyme-like activities) of NNMs. The selected representative NNMs exhibit multienzyme-mimetic activity, indicating that they have the potentials for replacing specific enzymes in living systems. Currently, NNMs have been reportedly used as an antibactericidal $[60,61]$, an anti-inflammatory $[62,63]$, and a sedative $[64]$ owing to their unique physical and chemical properties, such as surface adsorption, electrocatalysis, and large specific surface area. All these applications are based on the reported physicochemical properties of NNMs. Here, we first report NNMs as a new type of nanozymes, which show a great

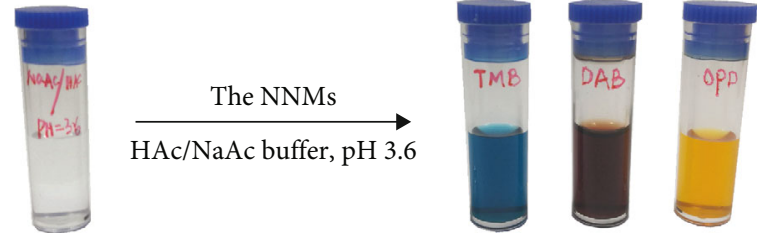

FIgURE 4: The NNMs catalyze the oxidation of peroxidase substrates (i.e., TMB, DAB, and OPD) in the presence of $\mathrm{H}_{2} \mathrm{O}_{2}$ to produce colorimetric reactions, showing the POD-like activity of NNMs toward typical peroxidase substrates.

potential application for biomedicine development in the future. For instance, it is well known that long-term infection of Helicobacter pylori in the stomach can cause peptic ulcer disease and stomach cancer $[65,66]$. And, it is of great significance to develop a medicine for eliminating Helicobacter pylori in the stomach. Montmorillonite has been used as a medicine for the treatment of diarrhea, indicating the possibility of its medical application in the stomach. We prospectively propose a concept of using montmorillonite for the sterilization of Helicobacter pylori in the stomach (Figure 6). Montmorillonite first adsorbs Helicobacter using its good adsorption performance, attaching Helicobacter pylori to its surface. Then, it exerts its peroxidase activity under the acidic conditions of the stomach, converting part of the ROS in the stomach into antibacterial factors for sterilization. However, the focus is on improving its enzyme-like activities and its capacity for loading corresponding drugs to improve its therapeutic effect.

Although the enzyme-like activity of NNMs has been discovered, there are still challenges to be addressed.

(1) The catalytic mechanisms of NNMs: the structure and morphology of the studied NNMs play a critical role in their surface electrochemical properties, adsorption capacity, and distribution of active sites. Thus, the deep understanding of the catalytic mechanisms will benefit the regulation and potential application of the catalytic activities of NNMs

(2) Uniformity: the SEM and TEM images show that the morphologies and sizes of the tested NNMs are not uniform, which will greatly limit their application in bioanalysis

(3) Exploring more types of enzyme-like activities, such as protease: in this work, we report the POD-, OXD-, CAT-, and SOD-like activities of NNMs. Many other types of enzyme-like activities remain to be explored for their broader applications 

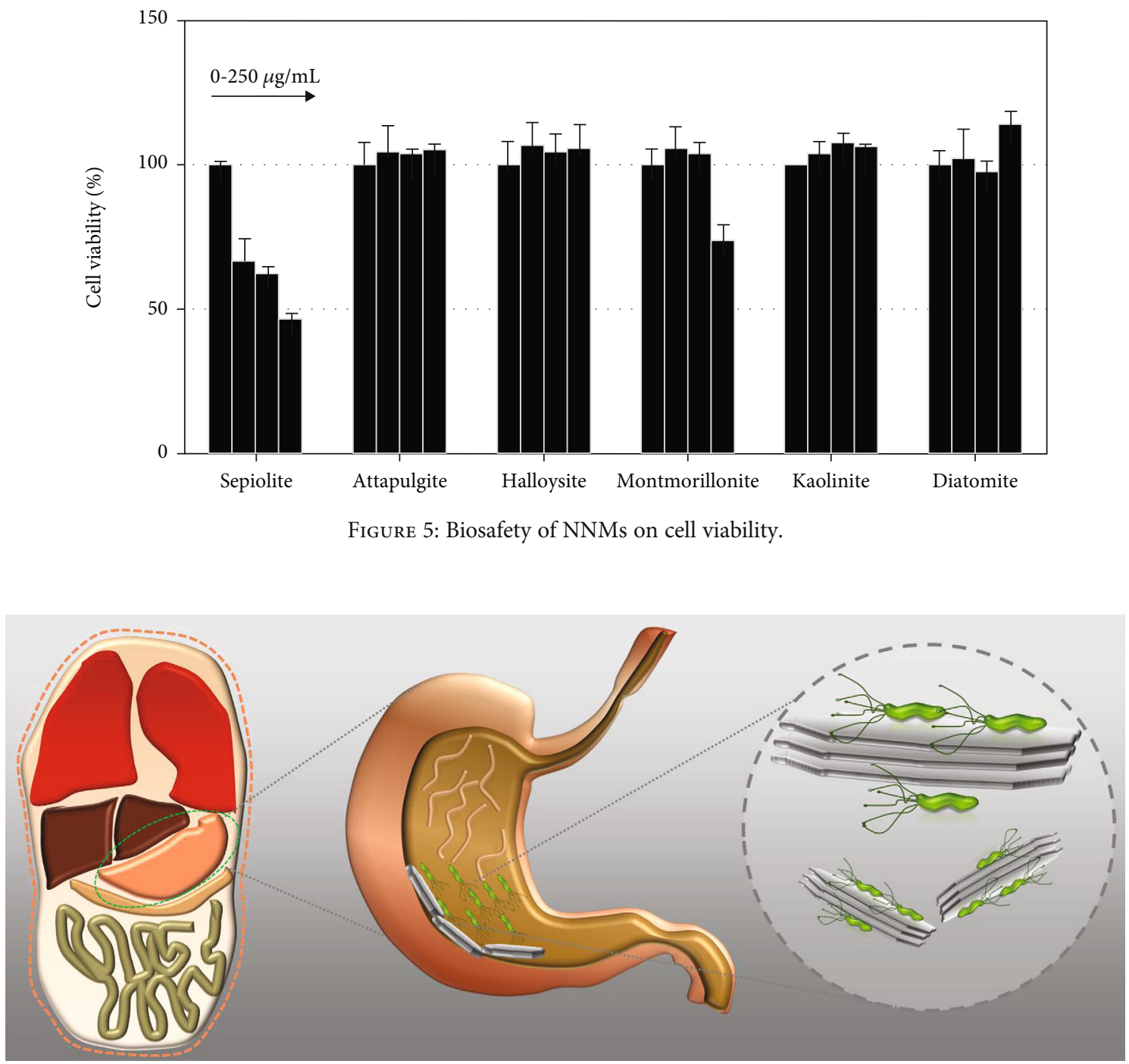

FIgURE 6: Schematic diagram of killing Helicobacter pylori in the stomach by montmorillonite.

Taken together, as a new type of natural and nontoxic nanomaterials, NNMs will play an important role in biomedicine and in the healthcare field with the deep understanding of their enzyme-like activities and physicochemical properties.

\section{Conclusion}

In summary, we characterize their morphology and enzymelike activities and assay their bioeffects on cell activity. And we first reveal that NNMs have the intrinsic enzyme-like activities (including POD-, CAT-, OXD-, and SOD-like activities), which can be used as an ideal substitute for natural enzymes. In addition, we test the biosafety of NNMs, and the results show that they have no or less cytotoxicity, showing their potential in biomedicine. We expect that NNMs, as a new type of nanozymes, can be used as multifunctional nanomaterials for biological applications and even for industries through combining their unique physicochemical properties with their intrinsic enzyme-like activity.

\section{Data Availability}

The data used to support the findings of this study are included within the article.

\section{Conflicts of Interest}

The authors declare no conflict of interest.

\section{Authors' Contributions}

F.F. and P.W. had the same contribution to the work. Y.Z., M.L., F.F., P.W., and Y. L. conceived and designed the experiments. Y.Z., M.L., and P.K. Chu revised and polished the paper. All authors discussed the results and commented on the manuscript. F.F. and P.W. contributed equally to this work. 


\section{Acknowledgments}

This work was supported by the National Natural Science Foundation of China (Nos. 21922203, 52072347, 51572246, 81722024, and 81571728), the National Key R\&D Program of China (No. 2017YFA0205501), the Key Research Program of Frontier Sciences (No. QYZDY-SSWSMC013), and the Youth Innovation Promotion Association (No. 2014078). Peixia Wang was supported in part by the Postdoctoral Fellowship of Peking-Tsinghua Center for Life Sciences.

\section{References}

[1] R. A. Sheldon and S. van Pelt, "Enzyme immobilisation in biocatalysis: why, what and how," Chemical Society Reviews, vol. 42, no. 15, pp. 6223-6235, 2013.

[2] M. E. Sowa, E. J. Bennett, S. P. Gygi, and J. W. Harper, "Defining the human deubiquitinating enzyme interaction landscape," Cell, vol. 138, no. 2, pp. 389-403, 2009.

[3] T. A. Soucy, P. G. Smith, M. A. Milhollen, A. J. Berger, and S. P. Langston, "An inhibitor of NEDD8-activating enzyme as a new approach to treat cancer," Nature, vol. 458, no. 7239, pp. 732-736, 2009.

[4] O. I. Wilner, Y. Weizmann, R. Gill, O. Lioubashevski, R. Freeman, and I. Willner, "Enzyme cascades activated on topologically programmed DNA scaffolds," Nature Nanotechnology, vol. 4, no. 4, pp. 249-254, 2009.

[5] T. T. Onder, N. Kara, A. Cherry et al., "Chromatin-modifying enzymes as modulators of reprogramming," Nature, vol. 483, no. 7391, pp. 598-602, 2012.

[6] H. Wei and E. Wang, "Nanomaterials with enzyme-like characteristics (nanozymes): next-generation artificial enzymes," Chemical Society Reviews, vol. 42, no. 14, pp. 6060-6093, 2013.

[7] M. Liang and X. Yan, "Nanozymes: from new concepts, mechanisms, and standards to applications," Accounts of Chemical Research, vol. 52, no. 8, pp. 2190-2200, 2019.

[8] L. Gao, J. Zhuang, L. Nie et al., "Intrinsic peroxidase-like activity of ferromagnetic nanoparticles," Nature Nanotechnology, vol. 2, no. 9, pp. 577-583, 2007.

[9] L. Gao and X. Yan, "Nanozymes: an emerging field bridging nanotechnology and biology," Science China. Life Sciences, vol. 59, no. 4, pp. 400-402, 2016.

[10] L. Feng, C. J. Musto, and K. S. Suslick, "A simple and highly sensitive colorimetric detection method for gaseous formaldehyde," Journal of the American Chemical Society, vol. 132, no. 12, pp. 4046-4047, 2010.

[11] B. Leng, L. Zou, J. Jiang, and H. Tian, "Colorimetric detection of mercuric ion $\left(\mathrm{Hg}^{2+}\right)$ in aqueous media using chemodosimeter-functionalized gold nanoparticles," Sensors and Actuators B: Chemical, vol. 140, no. 1, pp. 162-169, 2009.

[12] P. Roy, Z. H. Lin, C. T. Liang, and H. T. Chang, "Synthesis of enzyme mimics of iron telluride nanorods for the detection of glucose," Chemical Communications, vol. 48, no. 34, pp. 4079-4081, 2012.

[13] H. B. Na, J. H. Lee, and K. An, "Development of a T1 contrast agent for magnetic resonance imaging using $\mathrm{MnO}$ nanoparticles," Angewandte Chemie, vol. 46, no. 28, pp. 5397-5401, 2006.

[14] F. Yang, S. Hu, Y. Zhang et al., "A hydrogen peroxideresponsive $\mathrm{O}_{2}$ nanogenerator for ultrasound and magnetic- resonance dual modality imaging," Advanced Materials, vol. 24, no. 38, pp. 5205-5211, 2012.

[15] H. J. Kwon, M.-Y. Cha, D. Kim et al., "Mitochondria-targeting ceria nanoparticles as antioxidants for Alzheimer's disease," ACS Nano, vol. 10, no. 2, pp. 2860-2870, 2016.

[16] K. Fan, J. Xi, L. Fan et al., "In vivo guiding nitrogen-doped carbon nanozyme for tumor catalytic therapy," Nature Communications, vol. 9, no. 1, p. 1440, 2018.

[17] N. Singh, M. A. Savanur, S. Srivastava, P. D. P. D'Silva, and P. D. G. Mugesh, "A redox modulatory $\mathrm{Mn}_{3} \mathrm{O}_{4}$ nanozyme with multi-enzyme activity provides efficient cytoprotection to human cells in a Parkinson's disease model," Angewandte Chemie, vol. 56, no. 45, pp. 14267-14271, 2017.

[18] M. F. Hochella Jr., D. W. Mogk, J. Ranville et al., "Natural, incidental, and engineered nanomaterials and their impacts on the Earth system," Science, vol. 363, no. 6434, pp. 1414-1414, 2019.

[19] M. O. Figueiredo, T. P. Silva, and J. P. Veiga, "Natural nanomaterials: reappraising the elusive structure of the nano-sized mineral ferrihydrite through X-ray absorption spectroscopy at the iron K-edge," Materials Science Forum, vol. 730-732, pp. 931-935, 2012.

[20] T. Chen, Q. Xie, H. Liu, J. Xie, and Y. Zhou, "Nano-minerals and nano-mineral resources," Diqiu Kexue Zhongguo Dizhi Daxue Xuebao/earth Science Journal of China University of Geosciences, vol. 43, no. 5, pp. 1439-1449, 2018.

[21] L. Liao, "New development of functional mineral materials in China," Kuei Suan Jen Hsueh Pao/Journal of the Chinese Ceramic Society, vol. 39, no. 9, pp. 1523-1530, 2011.

[22] X. Liu, F. Zhang, X. Jing et al., "Complex silica composite nanomaterials templated with DNA origami," Nature, vol. 559, no. 7715, pp. 593-598, 2018.

[23] P. K. Sarkar and A. K. Chaudhary, "Ayurvedic Bhasma: the most ancient application of nanomedicine," Journal of Entific \& Industrial Research, vol. 69, no. 12, pp. 901-905, 2010.

[24] Z. Wang, Y. Zhao, Y. Luo et al., “Attapulgite-doped electrospun poly(lactic-co-glycolic acid) nanofibers enable enhanced osteogenic differentiation of human mesenchymal stem cells," RSC Advances, vol. 5, no. 4, pp. 2383-2391, 2014.

[25] S. Han, F. Liu, J. Wu et al., "Targeting of fluorescent palygorskite polyethyleneimine nanocomposite to cancer cells," Applied Clay Science, vol. 101, no. nov, pp. 567-573, 2014.

[26] B. Wicklein, P. Aranda, E. Ruiz-Hitzky, and M. Darder, "Hierarchically structured bioactive foams based on polyvinyl alcohol-sepiolite nanocomposites," Journal of Materials Chemistry B, vol. 1, no. 23, pp. 2911-2920, 2013.

[27] C. Hu, J. Song, Z. You, Z. S. Luan, and W. Li, "Zinc oxidemontmorillonite hybrid influences diarrhea, intestinal mucosal integrity, and digestive enzyme activity in weaned pigs," Biological Trace Element Research, vol. 149, no. 2, pp. 190196, 2012.

[28] D. Hou, S. Hu, Y. Huang et al., "Preparation and in vitro study of lipid nanoparticles encapsulating drug loaded montmorillonite for ocular delivery," Applied Clay Science, vol. 119, no. JAN, pp. 277-283, 2016.

[29] M. Terracciano, M. Napolitano, L. de Stefano, A. C. de Luca, and I. Rea, "Gold decorated porous biosilica nanodevices for advanced medicine," Nanotechnology, vol. 29, no. 23, article 235601, 2018.

[30] Y.-Z. Wang, H. Zhong, X.-R. Li et al., "Nonenzymatic electrochemiluminescence glucose sensor based on quenching effect 
on luminol using attapulgite- $\mathrm{TiO}_{2}$," Sensors and Actuators $B$ : Chemical, vol. 230, pp. 449-455, 2016.

[31] C. Cheng, Y. Gao, W. Song, Q. Zhao, H. Zhang, and H. Zhang, "Halloysite nanotube-based $\mathrm{H}_{2} \mathrm{O}_{2}$-responsive drug delivery system with a turn on effect on fluorescence for real-time monitoring," Chemical Engineering Journal, vol. 380, article 122474, 2020.

[32] W. Sajjad, T. Khan, M. Ul-Islam et al., "Development of modified montmorillonite-bacterial cellulose nanocomposites as a novel substitute for burn skin and tissue regeneration," Carbohydrate Polymers, vol. 206, pp. 548-556, 2019.

[33] B. Zhang, Y. Wan, C. Li, J. Wang, and J. Liu, "Chitosan-halloysite hybrid-nanotubes: horseradish peroxidase immobilization and applications in phenol removal," Chemical Engineering Journal, vol. 214, pp. 304-309, 2013.

[34] Y. G. Liang, L. Xu, J. Bao, K. A. Firmin, and W. Zong, "Attapulgite enhances methane production from anaerobic digestion of pig slurry by changing enzyme activities and microbial community," Renewable Energy, vol. 145, pp. 223-232, 2019.

[35] Y. Sun, G. Sun, Y. Xu et al., "Assessment of natural sepiolite on cadmium stabilization, microbial communities, and enzyme activities in acidic soil," Environmental Science \& Pollution Research, vol. 20, no. 5, pp. 3290-3299, 2013.

[36] K. Fan, C. Cao, Y. Pan, D. Lu, and D. Yang, "Magnetoferritin nanoparticles for targeting and visualizing tumour tissues," Nature Nanotechnology, vol. 7, no. 12, pp. 833-833, 2012.

[37] S. E. Kim, L. Zhang, K. Ma et al., "Ultrasmall nanoparticles induce ferroptosis in nutrient-deprived cancer cells and suppress tumour growth," Nature Nanotechnology, vol. 11, no. 11, pp. 977-985, 2016.

[38] E. C. Pratt, J. Grimm, and M. L. Guzman, "FDA-approved ferumoxytol displays anti-leukaemia efficacy against cells with low ferroportin levels," Nature Nanotechnology, vol. 14, pp. 616-622, 2019.

[39] J. L. Valentin, M. A. Lopez-Manchado, A. Rodriguez, P. Posadas, and L. Ibarra, "Novel anhydrous unfolded structure by heating of acid pre-treated sepiolite," Applied Clay Science, vol. 36, no. 4, pp. 245-255, 2007.

[40] B. Li, W. Li, Q. Zhang, W. Weng, and H. Wan, "Attapulgite as natural catalyst for glucose isomerization to fructose in water," Catalysis Communications, vol. 99, pp. 20-24, 2017.

[41] L. Tan, A. Tang, Y. Zou et al., " $\mathrm{Sb}_{2} \mathrm{Se}_{3}$ assembling $\mathrm{Sb}_{2} \mathrm{O}_{3} @$ attapulgite as an emerging composites for catalytic hydrogenation of p-nitrophenol," Scientific Reports, vol. 7, no. 1, p. 3281, 2017.

[42] Y. Liu, X. Wang, Y. Wang et al., "Ultra-low thermal conductivities of hot-pressed attapulgite and its potential as thermal insulation material," Applied Physics Letters, vol. 108, no. 10, pp. 405-533, 2016.

[43] A. Rapacz-Kmita, K. Foster, M. Mikolajczyk, M. Gajek, E. Stodolak-Zych, and M. Dudek, "Functionalized halloysite nanotubes as a novel efficient carrier for gentamicin," Materials Letters, vol. 243, no. MAY15, pp. 13-16, 2019.

[44] B. E. Gyan, N. Emmanuel, D. A. David et al., "Modified halloysite nanoclay as a vehicle for sustained drug delivery," Heliyon, vol. 4, no. 7, article e00689, 2018.

[45] Y. Lvov, A. Aerov, and R. Fakhrullin, "Clay nanotube encapsulation for functional biocomposites," Advances in Colloid and Interface Science, vol. 207, no. 1, pp. 189-198, 2013.

[46] M. Zhao, L. Wei, Y. Zheng, M. Liu, J. Wang, and Y. Qiu, "Structural effect of imidazolium-type ionic liquid adsorption to montmorillonite," Science of the Total Environment, vol. 666, pp. 858-864, 2019.

[47] E. Manias, A. Touny, L. Wu, K. Strawhecker, B. Lu, and T. C. Chung, "Polypropylene/montmorillonite nanocomposites. Review of the synthetic routes and materials properties," Chemistry of Materials, vol. 13, no. 10, pp. 3516-3523, 2001.

[48] M. Batistella, B. Otazaghine, R. Sonnier, C. Petter, and J.M. Lopez-Cuesta, "Fire retardancy of polypropylene/kaolinite composites," Polymer Degradation and Stability, vol. 129, pp. 260-267, 2016.

[49] M. Li, Y. H. Lao, R. L. Mintz et al., “A multifunctional mesoporous silica-gold nanocluster hybrid platform for selective breast cancer cell detection using a catalytic amplificationbased colorimetric assay," Nanoscale, vol. 11, no. 6, pp. 2631-2636, 2019.

[50] H. Zhao, X. Zhang, D. Zhou et al., "Collagen, polycaprolactone and attapulgite composite scaffolds for in vivo bone repair in rabbit models," Biomedical Materials, vol. 15, no. 4, article 045022, 2020.

[51] J. Wang, G. Zhang, S. Qiao, and J. Zhou, "Magnetic Fe ${ }^{0}$ /iron oxide-coated diatomite as a highly efficient adsorbent for recovering phosphorus from water," Chemical Engineering Journal, vol. 412, article 128696, 2021.

[52] Y. Lin, X. Wang, J. Liu, and J. D. Miller, "Natural halloysite nano-clay electrolyte for advanced all-solid-state lithium- sulfur batteries," Nano Energy, vol. 31, pp. 478-485, 2017.

[53] W. Li, Y. Nan, Z. Zhang, Q. You, and Z. Jin, "Hydrophilicity/ hydrophobicity driven $\mathrm{CO}_{2}$ solubility in kaolinite nanopores in relation to carbon sequestration," Chemical Engineering Journal, vol. 398, article 125449, 2020.

[54] Z. Li, P. H. Chang, W. T. Jiang, and J. S. Jean, “The multimechanisms and interlayer configurations of metoprolol uptake on montmorillonite," Chemical Engineering Journal, vol. 360, pp. 325-333, 2019.

[55] J. Cervini-Silva, M. T. Ramírez-Apan, S. Kaufhold et al., "Cell growth underpinned by sepiolite," Applied Clay Science, vol. 137, no. MAR, pp. 77-82, 2017.

[56] W. Sun, X. Sun, N. Akhtar et al., "Attapulgite nanorods assisted surface engineering for separator to achieve highperformance lithium-sulfur batteries," Journal of Energy Chemistry, vol. 48, pp. 364-374, 2020.

[57] D. Soltermann, M. Marques Fernandes, B. Baeyens et al., "Fe(II) uptake on natural montmorillonites. I. Macroscopic and spectroscopic characterization," Environmental Science \& Technology, vol. 48, no. 15, pp. 8688-8697, 2014.

[58] C. M. Subramaniyam, N. R. Srinivasan, Z. Tai, H. K. Liu, J. B. Goodenough, and S. X. Dou, "Self-assembled porous carbon microparticles derived from halloysite clay as a lithium battery anode," Journal of Materials Chemistry A, vol. 5, no. 16, pp. 7345-7354, 2017.

[59] X. Ye, S. Kang, H. Wang, H. Li, and H. Zhao, "Modified natural diatomite and its enhanced immobilization of lead, copper and cadmium in simulated contaminated soils," Journal of Hazardous Materials, vol. 289, pp. 210-218, 2015.

[60] J. F. Boelter and A. Brandelli, "Innovative bionanocomposite films of edible proteins containing liposome-encapsulated nisin and halloysite nanoclay," Colloids and Surfaces. B, Biointerfaces, vol. 145, pp. 740-747, 2016.

[61] S. Holešová, J. Štembírek, L. Bartošová et al., “Antibacterial efficiency of vermiculite/chlorhexidine nanocomposites and results of the in vivo test of harmlessness of vermiculite," 
Materials Science and Engineering: C, vol. 42, pp. 466-473, 2014.

[62] V. Maria-Teresa, A. Carola, C. Pilar, C. Giuseppe, and V. Cesar, "Supramolecular structure of 5-aminosalycilic acid/ halloysite composites," Journal of Microencapsulation, vol. 26, no. 3, pp. 279-286, 2008.

[63] M. T. Viseras, C. Aguzzi, P. Cerezo, C. Viseras, and C. Valenzuela, "Equilibrium and kinetics of 5-aminosalicylic acid adsorption by halloysite," Microporous and Mesoporous Materials, vol. 108, no. 1-3, pp. 112-116, 2008.

[64] G. Gereli, Y. Seki, İ. Murat Kuşoğlu, and K. Yurdakoç, "Equilibrium and kinetics for the sorption of promethazine hydrochloride onto K10 montmorillonite," Journal of Colloid Science, vol. 299, no. 1, pp. 155-162, 2006.

[65] R. Kinoshita-Daitoku, K. Kiga, M. Miyakoshi et al., "A bacterial small RNA regulates the adaptation of Helicobacter pylori to the host environment," Nature Communications, vol. 12, no. 1, p. 2085, 2021.

[66] E. S. Cunha, X. Chen, M. Sanz-Gaitero, D. J. Mills, and H. Luecke, "Cryo-EM structure of _Helicobacter pylori_ urease with an inhibitor in the active site at $2.0 \AA$ resolution," Nature Communications, vol. 12, no. 1, p. 230, 2021. 